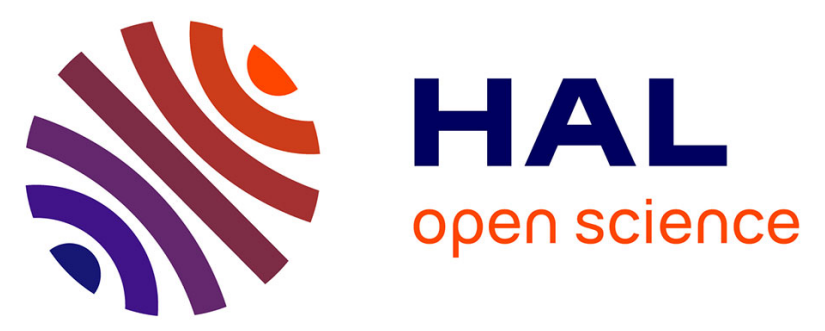

\title{
A straightforward synthesis of a new family of molecules: 2,5,8-trialkoxyheptazines. Application to photoredox catalyzed transformations
}

Tuan Le, Laurent Galmiche, Geraldine Masson, Clémence Allain, Pierre Audebert

\section{To cite this version:}

Tuan Le, Laurent Galmiche, Geraldine Masson, Clémence Allain, Pierre Audebert. A straightforward synthesis of a new family of molecules: 2,5,8-trialkoxyheptazines. Application to photoredox catalyzed transformations. Chemical Communications, 2020, 56 (73), pp.10742-10745. 10.1039/D0CC05118G. hal-03009616

\section{HAL Id: hal-03009616 https://hal.science/hal-03009616}

Submitted on 23 Nov 2020

HAL is a multi-disciplinary open access archive for the deposit and dissemination of scientific research documents, whether they are published or not. The documents may come from teaching and research institutions in France or abroad, or from public or private research centers.
L'archive ouverte pluridisciplinaire HAL, est destinée au dépôt et à la diffusion de documents scientifiques de niveau recherche, publiés ou non, émanant des établissements d'enseignement et de recherche français ou étrangers, des laboratoires publics ou privés. 


\section{A Straightforward synthesis of a new family of molecules: 2,5,8- trialkoxyheptazines. Application to photoredox catalyzed transformations}

Received 00th January 20xx, Accepted 00th January 20xx DOI: $10.1039 / x 0 x \times 00000 x$
We have prepared several 2,5,8-trialkoxyheptazines starting from the soluble precursor 2,5,8-tris(3,5-diethylpyrazolyl)-heptazine. We present their syntheses along with their promising spectroscopic and electrochemical properties, which demonstrate large band gaps and high reduction potentials altogether. Following, we provide a short assessment of the promising ability of one of these molecules to perform catalytic oxidation test-reactions.

Heptazines (Scheme 1) are a fascinating family of high nitrogen aromatic fused tricyclic compounds because of their high nitrogen content, associated to their benzene-type aromaticity, which make them a unique case of electron deficient organic compounds. Their high electron deficiency lies between the triazines and the tetrazines, two other classes of analogous widely studied heterocycles. Because of this reason, heptazines can be reduced, sometimes reversibly, at a relatively high potentials ${ }^{1}$, which opens interest in view of application for photovoltaic devices. Actually, despite their nitrogen to carbon $(\mathrm{N} / \mathrm{C})$ ratio of 1.15 is closer to triazines (equal to 1 ), their reduction potential is surprisingly closer to tetrazines than triazines. ${ }^{2}$ Likely, the smaller contribution to the electron affinity linked to the $\mathrm{N} / \mathrm{C}$ ratio is balanced by the electron delocalization over the three rings. In addition, many of the relatively rare heptazines known to date present desirable properties. Especially, their fluorescence emission ${ }^{3}$ has been exploited in liquid crystalline materials ${ }^{4}$ and OLEDs devices. ${ }^{5}$

Finally, even more attracting, heptazine polymers have demonstrated outstanding photocatalytic properties, ${ }^{6,7}$ and the heptazine core might well be one of the rare molecular

\footnotetext{
a. T. Le, Dr L. Galmiche, Dr C. Allain, Prof. P. Audebert

PPSM, ENS Paris-Saclay, CNRS UMR 8531, 61, Avenue du Président Wilson, 94235

Cachan cedex, France. E-mail: audebert@ppsm.ens-cachan.fr

b. T. Le, G. Masson

Institut de Chimie des Substances Naturelles, CNRS, UPR2301, Université Paris

Saclay, 1 Avenue de la Terrasse, 91198 Gif-sur-Yvette cedex, France

c. Prof. P. Audebert, XLIM, UMR CNRS 7252 123, avenue Albert Thomas - 87060 LIMOGES CEDEX

† Footnotes relating to the title and/or authors should appear here.

Electronic Supplementary Information (ESI) available: [details of any supplementary information available should be included here]. See DOI: 10.1039/x0xx00000x
}

platforms which could give birth to molecular catalysts able to perform water splitting8-10, the holy Grail of all photocatalytic processes. Two recent reviews have made a point on this highly interesting family of heterocyclic compounds ${ }^{11,12}$. In line with these facts, organic photocatalysis also has recently known a fast regain of interest ${ }^{13-15}$, given the price and limited availability of transition metals photocatalysts ${ }^{16}$. The use of heptazine derivatives as photooxidants appears therefore as an obvious alternative to classical organometallic photooxidants. ${ }^{17}$

These facts have therefore stimulated considerable interest in the preparation of novel heptazines. However, the synthetic chemistry of heptazines is much more challenging than the one of its parent aforementioned heterocycles ${ }^{18}$. Almost all the synthetic methodologies reported to date start only from the trichloroheptazine ${ }^{19,20}$, (sometimes designed as cyameluric acid chloride). However, although effective, there are several drawbacks to the use of trichloroheptazine: (1) Its high sensitivity to hydrolysis and poor solubility in most common solvents and (2) its delicate synthetic route originally reported by Kroke et al. ${ }^{21}$ for which dedicated equipment is required, for safety reasons. To overcome this limitation, we recently reported the facile synthesis of a new heptazine derivative, 2,5,8-tris(3,5-diethyl-pyrazol-1-yl)-heptazine ${ }^{2}$ (Scheme 1, designed by 3PyHept in the following), possessing exchangeable diethylpyrazolyl leaving groups which can serve as a key intermediate to access several new heptazines derivatives by nucleophilic substitution, with various amines, aliphatic and aromatic thiols ${ }^{2}$.

In this article, we report our development in synthesis of new heptazines bearing various alkoxy groups. The resulting family of molecules (1a-e, Scheme 1), outside the unique member 2,5,8-triphenoxyheptazine ${ }^{22}$, has been unknown until now. These molecules emit a blue fluorescence, with reasonable quantum yields in the $20 \%$ range in dichloromethane solution, and present mild to strongly oxidizing excited states, according to the electron deficiency of the alcohol substituted. As a consequence, we report along, with the molecule of this family displaying the strongest oxidant character, a couple of 
preliminary examples of their photocatalytic activity on unprecedented examples with organic photocatalysts.
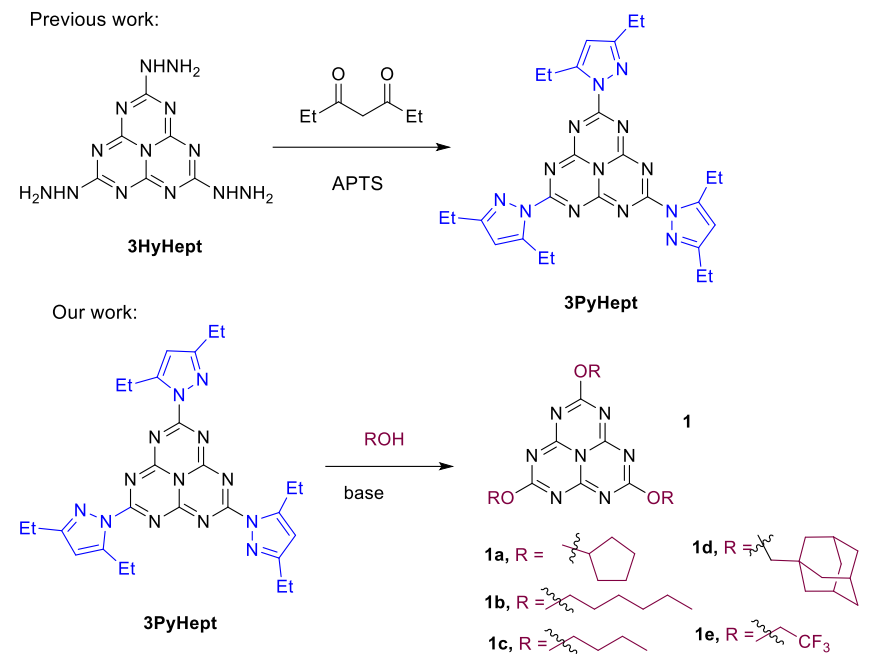

Scheme 1. Synthesis of alkoxyheptazines

The synthesis of trialkoxyheptazines occurs straightforwardly via a nucleophilic substitution reaction on 2,5,8-tris(3,5-diethylpyrazol-1-yl)-heptazine (3PyHept), which is less reactive than trichloroheptazine, and therefore base activation has to be used to promote the substitution reaction of pyrazoles. This is very similar than previously noticed by us with dichlorotetrazine. ${ }^{23-25}$ In dichlorotetrazine, the chlorines are less reactive than in trichloroheptazine; therefore, for substitution with alcohols, collidine is needed for the first substitution step, and DMAP for the second one. With 3PyHept, all pyrazoles more or less display the same reactivity than chlorines with tetrazines, therefore collidine, or DMAP were found to be proper catalysts altogether. More specifically, we have been able to react 3PyHept with linear primary alcohols (hexan-1-ol, butan-1-ol or trifluoroethanol) using 2,4,6-collidine as a base to obtain the corresponding heptazines $\mathbf{1 b}, \mathbf{1} \mathbf{c}$ and $\mathbf{1 e}$ with average to excellent yields. For more hindered alcohols (bulky or ramified), DMAP was used and heptazines 1a and 1c could be obtained with yields around $40 \%$ (see ESI for details).

We have performed electrochemical reduction of all the heptazines $1\left(\mathrm{Ag} / \mathrm{AgCl}\right.$ reference, checked vs ferrocene, $\mathrm{E}^{\circ}$ $(\mathrm{Fc} / \mathrm{Fc}+)=0.325 \mathrm{~V})$; the redox potentials are all equal to approximatively $-2.2 \mathrm{~V}$ for standard alcohols (estimation \pm 50 $\mathrm{mV}$, since reversible CV's were not obtainable for these compounds), with the obvious exception of $1 \mathbf{e}$ which is reduced (reversibly) at $-1.55 \mathrm{~V}$. Not surprisingly, all derivatives from aliphatic alcohols are reduced at the same potentials, as a result of analogous electronic effects. The only exception is the trifluoroethyl (TFE) derivative, which is reduced at a potential about $0.7 \mathrm{~V}$ higher, as a result of the strong electronwithdrawing effect of the trifluoromethyl groups, as already observed with tetrazines ${ }^{26}$. The relatively low redox potential of the standard alkoxyheptazines suggests that these molecules could behave as interesting platforms for substitution on heptazines with strong nucleophiles (e.g. Grignard reagents), since electron transfer with electron rich nucleophiles should be blocked, while substitution chemistry may remain possible. On the other hand, (see next part) the relatively high potential of
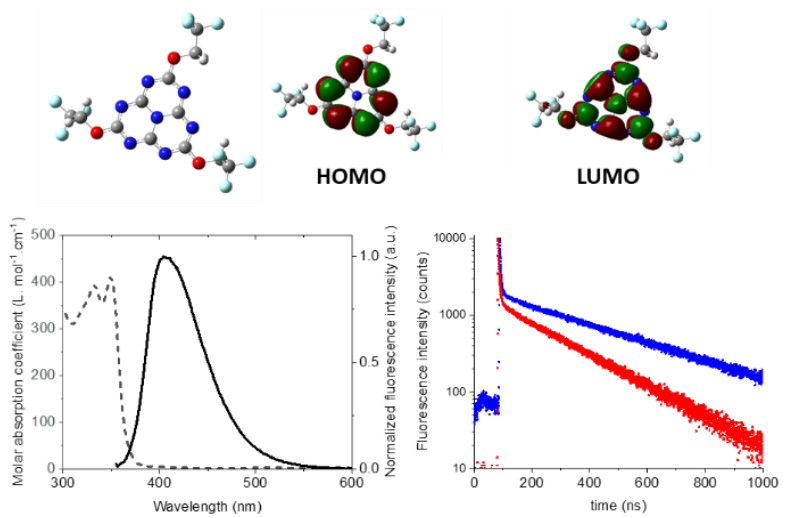

the TFE-heptazine is clearly promising for photocatalytic properties.

Figure 1: for heptazine 1e optimized geometry, HOMO and LUMO representations (top), low energy UV-Vis absorption band (dashed line) and fluorescence emission (plain line) in dichloromethane (bottom left); fluorescence decay in aerated dichloromethane (in red) and after 5 min degassing with $\mathrm{Ar}$ (in blue) (bottom right)

The spectroscopic characteristics of heptazines have been investigated in DCM solution. All compounds absorb light in the UV with an intense $\left(\varepsilon 2.10^{4} \mathrm{~L}\right.$. $\left.\mathrm{mol}^{-1} \cdot \mathrm{cm}^{-1}\right)$ absorption band around $270 \mathrm{~nm}$ and a low energy weaker band around $340 \mathrm{~nm}$ with a molar extinction coefficient $\varepsilon$ between 400 and $500 \mathrm{~L}$. $\mathrm{mol}^{-1} \cdot \mathrm{cm}^{-1}$ (see figure 1 and table 1 ). As expected, the positions and intensities only weakly depend on the nature of the alkoxy substituent. The results are summarized on the Table 1 below. All trialkoxyheptazines display a broad fluorescence emission band in the visible with a maximum between 408 and $412 \mathrm{~nm}$ depending on the substituent. These compounds display (Table 1) the strongest emission of all reported heptazines to date, at the exception of the aryl heptazines reported by $\mathrm{C}$. Adachi et $\mathrm{al}^{3,27}$. To our delight, all the trialkoxyheptazines studied display very long fluorescent decay times (table 1), that significantly increase upon degassing the solution with argon (figure 1 , bottom right), which strongly suggests that these compounds are TADF emitters. In all cases, the fluorescent decays can be fitted with two exponentials, which is indicative of several emissive conformers and will be further investigated.

DFT and TD-DFT calculations were conducted at the B3LYP 6$311 \mathrm{G}+(\mathrm{d}, \mathrm{p})$ level of theory for compound $\mathbf{1 c}$ and $\mathbf{1 e}$. Interestingly, the LUMO of compound 1 e $(-2.79 \mathrm{eV})$ is significantly lower in energy than the LUMO of compound 1c $(-2.32 \mathrm{eV})$ which is in line with the reduction potentials experimentally measured. The absorption bands (see ESI) are correctly predicted by calculations, which allows us to attribute the lowest absorption band to a HOMO-LUMO transition. Examination of the frontier orbitals (see figure 1, top and ESI) reveals that the HOMO-LUMO transition has an $n-\pi^{*}$ character, as already demonstrated for other heptazine derivatives ${ }^{3}$ which is fully consistent with its low molar extinction coefficient and long fluorescence lifetimes, even in aerated solution. Furthermore, TD-DFT calculations reveal that for heptazine 1c 
and 1e, the first triplet and singlet excited states, both of $n-\pi^{*}$ character, are close enough in energy (energy gaps of 110 and $1040 \mathrm{~cm}^{-1}$ ) to favour thermally activated delayed fluorescence.

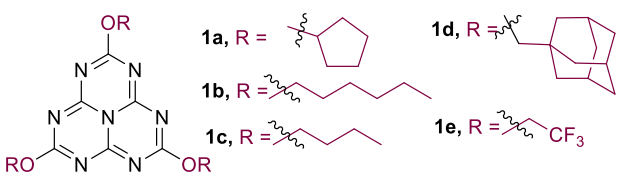

\begin{tabular}{|c|c|c|c|c|}
\hline compound & $\begin{array}{l}\varepsilon / \mathrm{L} \cdot \mathrm{mol}^{-1} \cdot \mathrm{cm}^{-1} \\
\left(\lambda_{\text {abs }}\right)\end{array}$ & $\begin{array}{l}\text { QY } \\
\left(\lambda_{\mathrm{em}}\right)\end{array}$ & $\begin{array}{l}\tau_{\mathrm{i}}(\mathrm{ai}) \\
\text { (air) }\end{array}$ & $\begin{array}{l}\tau_{l}(\mathrm{ai}) \\
(\mathrm{Ar})\end{array}$ \\
\hline $1 a$ & $\begin{array}{l}19600 \\
(272 \mathrm{~nm}) \\
490(348 \mathrm{~nm})\end{array}$ & $\begin{array}{l}0.21 \\
(412 \mathrm{~nm})\end{array}$ & $\begin{array}{l}150 \mathrm{~ns} \\
(0.37) \\
27 \mathrm{~ns} \\
(0.06) \\
2.1 \mathrm{~ns} \\
(0.58)\end{array}$ & $\begin{array}{l}394 \mathrm{~ns} \\
(0.39) ; \\
35 \mathrm{~ns} \\
(0.61)\end{array}$ \\
\hline $1 b$ & $\begin{array}{l}18200 \\
(275 \mathrm{~nm}) \\
490(331 \mathrm{~nm})\end{array}$ & $\begin{array}{l}0.15 \\
(409 \mathrm{~nm})\end{array}$ & $\begin{array}{l}148 \mathrm{~ns} \\
(0.82) ; \\
26 \mathrm{~ns} \\
(0.18)\end{array}$ & $\begin{array}{l}440 \mathrm{~ns} \\
(0.35) ; \\
35 \mathrm{~ns} \\
(0.65)\end{array}$ \\
\hline $1 c$ & $\begin{array}{l}21000 \\
(270 \mathrm{~nm}) \\
510(342 \mathrm{~nm})\end{array}$ & $\begin{array}{l}0.24 \\
(408 \mathrm{~nm})\end{array}$ & $\begin{array}{l}144 \mathrm{~ns} \\
(0.84) ; \\
35 \mathrm{~ns} \\
(0.16)\end{array}$ & $\begin{array}{l}460 \mathrm{~ns} \\
(0.50) \\
40 \mathrm{~ns} \\
(0.50)\end{array}$ \\
\hline $1 d$ & $\begin{array}{l}19000 \\
(270 \mathrm{~nm}) \\
470(341 \mathrm{~nm})\end{array}$ & $\begin{array}{l}0.23 \\
(410 \mathrm{~nm})\end{array}$ & $\begin{array}{l}149 \mathrm{~ns} \\
(0.33) ; \\
16 \mathrm{~ns} \\
(0.67)\end{array}$ & $\begin{array}{l}430 \mathrm{~ns} \\
(0.01) ; \\
21 \mathrm{~ns} \\
(0.99)\end{array}$ \\
\hline $1 e$ & $\begin{array}{l}22000 \\
(275 \mathrm{~nm}) \\
410(356 \mathrm{~nm})\end{array}$ & $\begin{array}{l}0.22 \\
(412 \mathrm{~nm})\end{array}$ & $\begin{array}{l}216 \mathrm{~ns} \\
(0.16) ; \\
24 \mathrm{~ns} \\
(0.84)\end{array}$ & $\begin{array}{l}374 \mathrm{~ns} \\
(0.39) ; \\
37 \mathrm{~ns} \\
(0.61)\end{array}$ \\
\hline
\end{tabular}

Table 1: Spectroscopic data for heptazines 1a-e in DCM solution (molar absorption coefficient $\varepsilon$, absorption maxima $\lambda_{\text {abs, fluorescence emission quantum yield } Q Y}$ determined using quinine sulphate as a reference, emission maxima $\lambda_{\mathrm{em}}$ and fluorescence emission decay times $\tau_{\mathrm{i}}(\mathrm{ns})$, together with their corresponding normalized preexponential factor $\mathrm{a}_{\mathrm{i}}$, measured on aerated and degassed solutions.

Combining the redox potential in the fundamental state with the bandgap of heptazine $1 \mathrm{e}$ (c.a. $3.4 \mathrm{eV}$, from the spectroscopic data) allows to estimate (neglecting the solvent influence) a redox oxidation potential of $+1.85 \mathrm{~V}(\mathrm{vs} \mathrm{Ag} / \mathrm{AgCl})$ that is, about $+1.8 \mathrm{~V}$ vs the SCE, for its excited state (Figure 2 ).

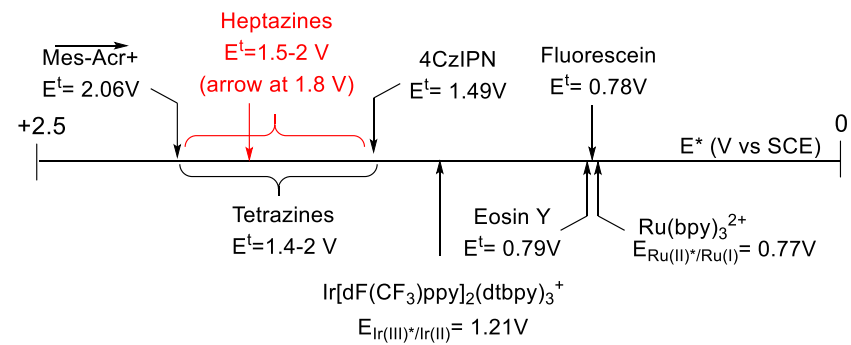

Figure 2. Electrochemical potentials estimated (beyond solvent effects) from the measurements of electrochemical and spectroscopic data for the excited states of various classical organic catalysts, including tetrazines and heptazines.
As aforementioned, heptazines are potentially excellent candidates for photocatalysis due to their increased light absorption across the near UV spectrum and longer excitedstate lifetimes in comparison to other organic photocatalysts. To highlight their specific reactivity, we evaluated them on reactions requiring strongly oxidative potentials. The organic dyes were tested in three acid-photocatalyzed oxidative reactions, including the $\mathrm{C}-\mathrm{S}$ bond functionalizations and the synthesis of nitrone.

Recently, we have demonstrated that 3,6-disubstituted stetrazines, were efficient organic photocatalysts to promote oxidative $\mathrm{C}-\mathrm{S}$ bond cleavage. ${ }^{28}$ To evaluate the performance of heptazines in this reaction, our initial reaction was carried out by subjecting benzylthioeter derivative $2 \mathbf{a}$ to our previous established conditions ${ }^{28}$ utilizing $1 \mathbf{e}$ as photocatalyst, oxygen as co-oxidant in acetonitrile at room temperature. Gratifyingly, the desired triarylated product $\mathbf{4}$ was obtained in $98 \%$ yield( figure 3). Control experiment showed that the reaction of $2 a$ proceeded in $9 \%$ conversion in the absence of $\mathrm{O}_{2}$. Although the formation of oxygen singlet cannot of course be excluded ${ }^{29}$, this result strongly supports a photocatalytic process, because otherwise only traces of products would have been observed, at best, in the absence of $\mathrm{O}_{2}$. Extension of this novel photocatalysed protocol to a $\alpha$-carbamoylsulfide $\mathbf{5}$ was also successful with trimethoxybenzene $\mathbf{3}$ or pyrazole $\mathbf{7}$ as nucleophiles, delivering products (6 and 8 ) that have potential applications in medicinal chemistry. ${ }^{28 \mathrm{c}}$ Encouraged by the result, we next turned our attention to develop a photocatalyzed DielsAlder reaction of $\mathbf{2} \mathbf{b}$ with the styrene $\mathbf{5}$ by using the same C-S bond cleavage method. A highly regioselective [4+2] oxidative cycloaddition product $\mathbf{1 0}$ was isolated in $80 \%$ yield and $3: 1 \mathrm{dr}$. Finally, we investigated whether these new organic dyes would be suitable for the oxidation of hydroxylamines into valuables nitrones. A short optimization study, established that 1e in TFE was effective for this oxidation, giving the nitrone $\mathbf{1 1}$ in $70 \%$ yield (figure 3 ).

These selected reactions demonstrate the high potential of these catalysts to promote challenging oxidation reactions. Despite yields are not yet optimized, this constitutes a preliminary demonstration that $\mathbf{1 e}$ heptazine is already amongst the most efficient purely organic photocatalysts known to date. 


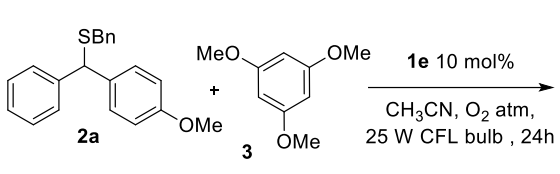

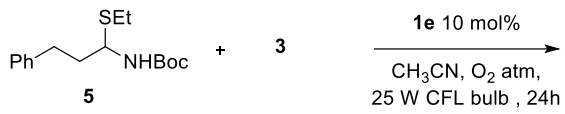

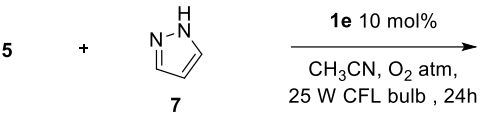<smiles>C=Cc1ccc(OC)cc1</smiles>

2b

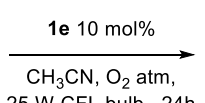
$25 \mathrm{~W}$ CFL bulb , 24h

$$
{ }_{11}^{\mathrm{Ph}} \widehat{\mathrm{OH}}_{\mathrm{Ph}}
$$

\section{1e $10 \mathrm{~mol} \%$}

utidine $(2,1 \mathrm{eq})$

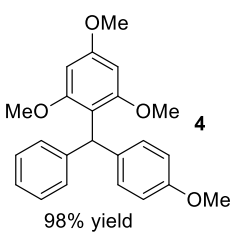

$98 \%$ yield<smiles>COc1cc(OC)c(C(CCc2ccccc2)NC(C)(C)C)c(OC)c1</smiles>

$60 \%$ yield<smiles>CC(C)(C)OCCNC(CCc1ccccc1)n1cccn1</smiles>

$60 \%$ yield

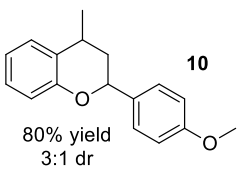

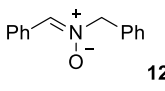

$80 \%$ yield
4

5. J. Li, H. Nomura, H. Miyazaki and C. Adachi, Chem. Commun., 2014, 50, 6174-6176.

6. V. W. Lau, M. B. Mesch, V. Duppel, V. Blum, J. Senker and B. V. Lotsch, J. Am. Chem. Soc., 2015, 137, 1064-1072.

7. Y. Wang, X. Wang and M. Antonietti, Angew. Chem. Int Ed., 2012, 51, 68-89.

8. J. Ehrmaier, T. N. V. Karsili, A. L. Sobolewski and W. Domcke, J. Phys. Chem. A, 2017, 121, 4754-4764.

10.

11.

12.

13

14.

25 W CFL bulb , 24 E. J. Rabe, K. L. Corp, A. L. Sobolewski, W. Domcke and C. W. Schlenker, J. Phys. Chem. Lett., 2018, 9, 6257-6261. N. Ullah, S. Chen, Y. Zhao and R. Zhang, J. Phys. Chem. Lett., 2019, 10, 4310-4316.

A. Schwarzer, T. Saplinova and E. Kroke, Coord. Chem. Rev., 2013, 257, 2032-2062.

Kumar, N. Sharma and K. Kailasam, J. Mater. Chem. A, 2018, 6, 21719-21728.

N. A. Romero and D. A. Nicewicz, Chem. Rev., 2016, 116, 10075-10166.

D. Ravelli, M. Fagnoni and A. Albini, Chem Soc Rev, 2013, 42, 97-113.

15. S. Fukuzumi and K. Ohkubo, Org Biomol Chem, 2014, 12 6059-6071.

16. C. K. Prier, D. A. Rankic and D. W. MacMillan, Chem. Rev. 2013, 113, 5322-5363.

Figure 3. Selected examples of photocatalyzed transformations

17. V. Santacroce, R. Duboc, M. Malacria, G. Maestri and G. Masson, Eur. J. Org. Chem., 2017, 2017, 2095-2098.

In conclusion, we have demonstrated that, besides the already prepared thio- and amino- derivatives, the yet unknown stable alkoxy derivatives of heptazine can be prepared from the recently discovered 2,5,8-tris(3,5-diethylpyrazol-1$y l)$ heptazine, thus extending further on the synthetic scope of this synthon. In addition, we have demonstrated the superior efficiency of the 2,5,8-tris(TFE)heptazine, which is already the most effective purely organic photooxidant known to date.

P. Audebert thanks the IUF (Institut Universitaire de France) for personal and financial support. T. Le thanks the Université ParisSaclay for doctoral fellowship.

Keywords: Heptazines; Photocatalysis; Delayed Fluorescence

\section{Conflicts of interest}

There are no conflicts to declare.

\section{Notes and references} P. Audebert, G. Clavier and C. Allain, in Prog. Heterocycl. Chem., eds. G. W. Gribble and J. A. Joule, Elsevier, 2017, vol. 29, pp. 483-518.

19. C. Posern, U. Böhme and E. Kroke, Z. Anorg. Allg. Chem., 2018, 644, 121-126.

$20 . \quad$ C. Posern, U. Bohme, J. Wagler, C. C. Hohne and E. Kroke Chem. Eur. J., 2017, 23, 12510-12518.

21. E. Kroke, M. Schwarz, E. Horath-Bordon, P. Kroll, B. Noll and A. D. Norman, New J. Chem., 2002, 26, 508-512.

22. M. R. Schwarz, H. Ehrenberg, M. A. Kloc and E. Kroke, Heterocycles, 2006, 68, 2499-2507.

23. P. Audebert, F. Miomandre, G. Clavier, M. C. Vernieres, S. Badré and R. Meallet-Renault, Chem. Eur. J., 2005, 11, 5667-5673.

24. Y. H. Gong, F. Miomandre, R. Meallet-Renault, S. Badre, L. Galmiche, J. Tang, P. Audebert and G. Clavier, Eur. J. Org. Chem., 2009, DOI: 10.1002/ejoc.200900964, 6121-6128.

25. G. Clavier and P. Audebert, Chem. Rev., 2010, 110, 32993314.

26. R. Ben Chaabane, R. Guermazi, G. Clavier, P. Audebert and A. Hedhli, Dyes and Pigments, 2014, 108, 64-69.

$27 . \quad J$. Li, T. Nakagawa, J. MacDonald, Q. Zhang, H. Nomura, H. Miyazaki and C. Adachi, Adv. Mater., 2013, 25, 3319-3323.

28. T. Le, T. Courant, J. Merad, C. Allain, P. Audebert and G. Masson, J. Org. Chem., 2019, 84, 16139-16146.

29. This is all the more possible since heptazines' long emission is most probably linked to a TADF process, and this is favor of the participation of the triplet state to their photochemistry. 